\title{
INVENTARISASI POTENSI MINERAL BATUAN SEBAGAI BAHAN GALIAN UNGGULAN DI KOTA JAYAPURA PROVINSI PAPUA
}

\author{
Bevie Marcho Nahumury \\ Jurusan Teknik Pertambangan, Fakultas Teknik, Universitas Cenderawasih
}

\begin{abstract}
ABSTRAK
Kota Jayapura salah satu wilayah di Provinsi Papua yang memiliki sebaran mineral batuan cukup potensial. Sebaran potensi sumberdaya mineral batuan antara lain batugamping, batuan beku ultra basa, batu lempung. Tujuan dari penelitian ini adalah untuk membuat peta potensi sebaran mineral batuan dengan menggunakan software ArcGIS 10.3. Kebutuhan akan mineral batuan khususnya batugamping sangat meningkat, hal ini dikarenakan proses pembangunan infrastruktur seperti jalan, jembatan dan pembangunan rumah toko (ruko). Menurut data salah satu perusahaan tambang peningkatan produksi batugamping secara nominal pemakaian batugamping adalah $43.200 \mathrm{~m}^{3}$ dengan harga jual adalah sebesar Rp. 400.000/ret yang dimanfaatkan oleh beberapa kontraktor pembangunan jalan. Dari seluruh potensi mineral batuan yang ada di Kota Jayapura, batugamping dan batuan beku ultrabasa berpeluang untuk diusahakan sebagai mineral unggulan.
\end{abstract}

Kata Kunci : Inventarisasi, Potensi, Galian Unggulan, Batuan, ArcGIS 10.3.

\begin{abstract}
Jayapura City is one of the regions in Papua Province which has quite a potential distribution of rock minerals. These mineral resources include limestone, ultra base igneous rock, and clay stone. The purpose of this study was to map out the distribution of these mineral rocks using the ArcGIS 10.3 software. The need for limestone greatly increases. This is due to the process of infrastructure development such as roads, bridges and the construction of stores. According to data from a mining company, limestone production reaches 43,200 m3 with a selling price of Rp. 400,000 / truck purchased by several construction contractors. Of all the potential rock minerals in Jayapura, limestone and ultramafic igneous rocks have the opportunity to be cultivated as superior minerals.
\end{abstract}

Keywords: Inventory, Potential, superior mined minerals, Rock, ArcGIS 10.3.

\section{A. PENDAHULUAN}

\section{A.1. Latar Belakang}

Kegiatan inventarisasi potensi mineral merupakan salah kegiatan awal dalam diagram alir penambangan yaitu kegiatan prospeksi. Dalam kegiatan prospeksi, kegiatan yang dilakukan adalah mencari dan menemukan bentuk, letak, posisi, sebaran dan luasan tentang keterdapatan suatu endapan mineral. Potensi endapan mineral yang terdapat di Kota Jayapura cukup potensial, mulai dari mineral batuan, logam dan non logam. Melihat sebaran yang ada maka keterdapatan endapan mineral batuan sebagai informasi mineral unggulan yaitu, batugamping, beku ultrabasa dan lempung.

Melihat peluang potensi sebaran endapan mineral batuan sebagai mineral unggulan di Kota Jayapura tersebut maka sangat perlu untuk dilakukan penelitian atau kajian studi inventarisasi 
potensi bahan galian unggulan secara umum untuk mengetahui lokasi keterdapatan, luasan areal sampai dengan nilai sumberdaya yang dimiliki. Selain itu hasil kajian ini juga sebagai data base mineral yang nantinya berguna untuk pemerintah Kota Jayapura dalam hal ini dinas terkait. Dipihak lain, pemerintah kota Jayapura sampai saat ini belum menangani secara serius potensi mineral batuan sebagai potensi mineral unggulan yang dimiliki, sehingga belum dapat dieksploitasi secara maksimal, belum ada usaha untuk meningkatakan mutu produk dari mineral unggulan. Selain itu terbatasnya sumberdaya manusia yang menangani sektor pertambangan yang kurang professional dan belum adanya konsep pengelolaan sumbedaya mineral yang dapat memberikan manfaat yang maksimal.

Pentingnya membuat data base inventarisasi mineral batuan adalah sebagai usulan atau bahan pertimbangan bagi pemerintah kota dalam hal penyusun kebijakan strategi termasuk rencana detail tata ruang kota dan KLHS (kajian lingkungan hidup strategis) dan juga dapat meningkatan pertumbuhan ekonomi bagi pemilik hak ulayat.

\section{A.2. Tujuan}

Berdasarkan latar belakang masalah, maka tujuan dari penelitian ini adalah untuk menginventarisasi keterdapatan endapan mineral batuan sebagai mineral unggulan dan membuat peta sebaran mineral dengan menggunakan softwere ArcGIS 10.3.

\section{A.3. Pendekatan Pemecahan Masalah}

Metode Pendekatan pemecahan masalah yang harus dilakukan adalah :

- Mengetahui permasalahan yang akan diselesaikan, dalam penelitian ini masalah yang akan diselesaikan adalah menginventarisir potensi sebaran mineral yang ada di Kota Jayapura.

- Metode penyelesaian masalah, dalam penelitian ini, tujuannya adalah bagimana meninventarisir potensi mineral batuan di Kota Jayapura, sehingga metode yang digunakan adalah survey dan pemetaan. Survey dan pemetaan dilakukan dengan menggunakan alat ukur seperti GPS dan Kompas Geologi, selain ini perlu mempelajari peta geologi lembar Jayapura untuk membandingkan kondisi dilapangan. Berdasarkan data survey dan pemetaan maka dilanjutkan dengan membuat peta sebaran potensi mineral batuan di Kota Jayapura dengan menggunakan softwere ArcGIS 10.3.

- Tercapainya tujuan permasalahan dengan metode yang digunakan, jika tidak perlu dilakukan peninjauan metode yang disesuaikan dengan permasalahan. Dalam penelitian ini outputnya adalah sebaran potensi mineral batuan.

\section{B. METODOLOGI PENELITIAN}

Metodologi penelitian yang dipergunakan dalam penelitian adalah :

1. Studi literatur

Studi literatur dilakukan dengan membaca penelitian-penelitian terdahulu mengenai inventarisasi potensi mineral khususnya endapan mineral batuan serta hal-hal yang terkait dengan kegiatan eksplorasi dan pemetaan dengan softwere ArcGIS 10.3.

2. Perumusan masalah

Menentukan hal-hal yang menjadi fokus perhatian pada penelitian mengenai studi inventarisasi potensi mineral khususnya endapan mineral batuan di Kota Jayapura.

3. Penelitian lapangan

Dilakukan untuk memperoleh data primer mengenai koordinat keterdapatan mineral, pemetaan topografi daerah penelitian, data eksplorasi daerah penelitian berupa kondisi geologi, morfologi dan jenis mineral batuan yang terdapat pada lokasi penelitian.

4. Pengumpulan data

Data-data yang dikumpulkan berupa : 
- Data Primer adalah data-data yang diambil dari pengamatan lapangan antara lain :

1. Data Koordinat Potensi Mineral.

2. Data Kondisi Geologi

3. Data Jenis Mineral Batuan

4. Pemetaan Topografi

- Data Sekunder adalah data-data pendukung penelitian bisa diambil dari lokasi penelitian dan juga berasal dari studi literatur, antara lain Peta geologi lembar Jayapura, tinjauan umum lokasi dan lain-lain.

5. Pengolahan dan Analisis data

Data yang dikumpulkan kemudian diolah dengan aplikasi softwere ArcGIS 10.3. untuk menghasilkan peta inventarisasi potensi mineral batuan sebagai mineral unggulan, perhitungan sumberdaya tiap lokasi keterdapatan mineral batuan.

6. Laporan Akhir

Penyusunan laporan sebagai hasil akhir dari penelitian mengenai Studi Inventarisasi Potensi Mineral Batuan sebagai Mineral Unggulan Di Kota Jayapura.

Untuk lebih jelas langkah-langkah penelitian dapat dilihat pada diagram penelitian dibawah ini :

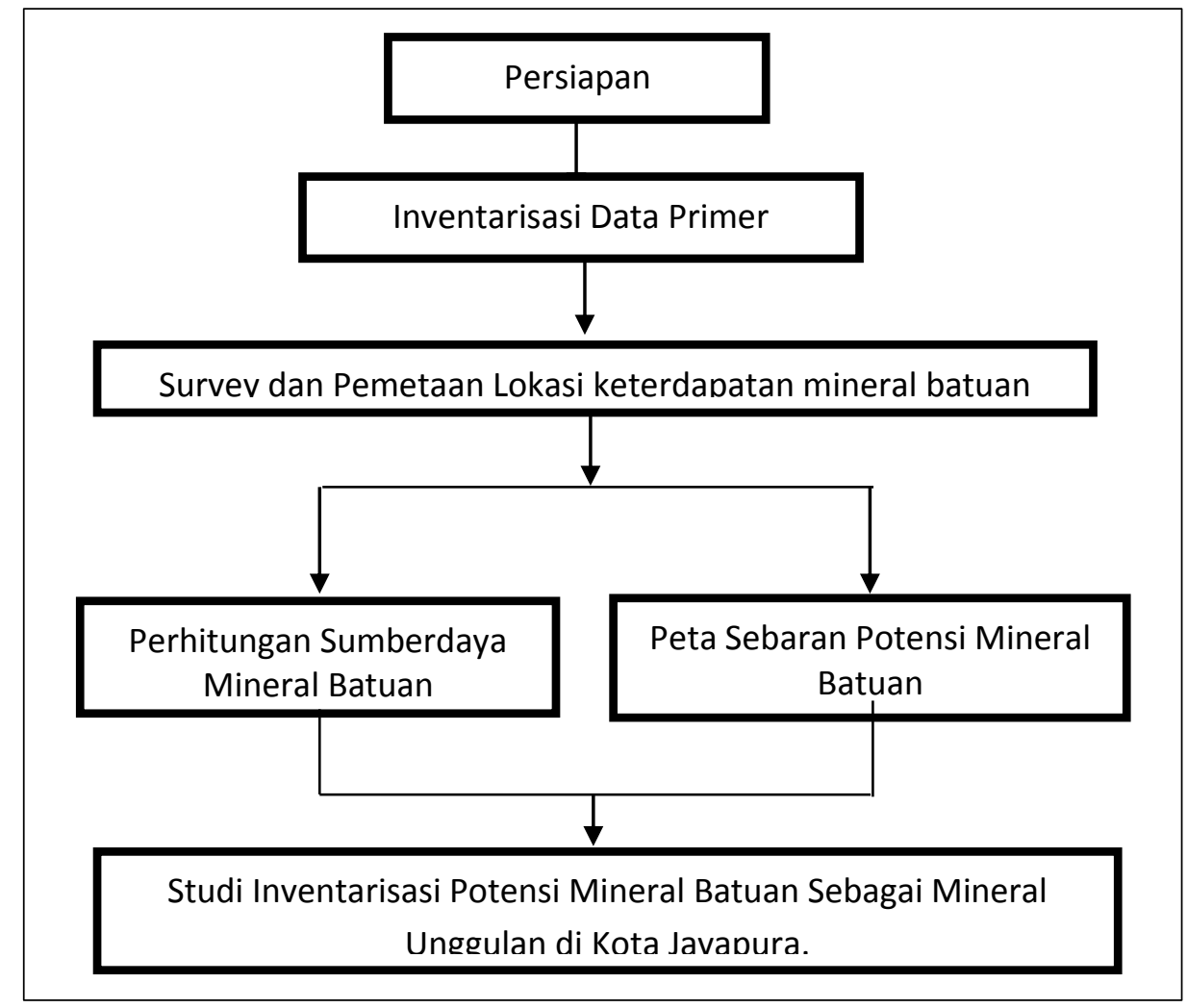

Gambar 1. Diagram Alir Penelitian

\section{HASIL DAN PEMBAHASAN}

\section{C1. Potensi}

Kota Jayapura memiliki sumberdaya mineral batuan seperti batugamping, beku ultrabasa dan lempung cukup potensial yang penyebarannya terdapat dibeberapa lokasi. Berdasarkan hasil survey, maka pemetaan potensi mineral adalah sebagai berikut :

1. Batugamping

Sumberdaya Batugamping terdapat dibeberapa wilayah, yaitu 
- Wilayah Polimak

Sumberdaya Batugamping di wilayah ini dengan jumlah cadangan sebesar 7.575.403,3 $\mathrm{m}^{3}$ dan telah diusahakan oleh CV. Thiak.

- Wilayah Argapura

Sumberdaya Batugamping di wilayah ini dengan jumlah cadangan sebesar 1.700.366,8 $\mathrm{m}^{3}$ dan telah diusahakan oleh beberapa investor namun dalam kondisi saat ini kegiatan penambangan sementara tidak aktif. Cadangan lain masih dalam tahap penyelidikan.

- Wilayah Koya Koso

Sumberdaya Batugamping di wilayah ini dengan jumlah cadangan sebesar 438.814,5 $\mathrm{m}^{3}$ dan telah diusahakan oleh investor dan pemilik hak ulayat setempat dan cadangan lain masih dalam tahap penyelidikan.

- Wilayah Waena (kamp. Wolker)

Sumberdaya Batugamping di wilayah ini dengan jumlah cadangan sebesar 2.673.135,3 $\mathrm{m}^{3}$ dan telah diusahakan oleh Investor tambang dan cadangan lain masih dalam tahap penyelidikan.

2. Beku Ultrabasa

Sumberdaya Batuan Beku Ultrabasa terdapat dibeberapa wilayah, yaitu

- Wilayah Kampung Yoka

Sumberdaya Beku Ultrabasa di wilayah ini dengan jumlah cadangan sebesar 5.724.008, $4 \mathrm{~m}^{3}$ dan telah diusahakan oleh PT. Jamer Mandiri dan cadangan lain masih dalam tahap penyelidikan.

- Wilayah Padang Bulan (Belakang Hola)

Sumberdaya Beku Ultrabasah di wilayah ini dengan jumlah cadangan sebesar 3.270.567,7 $\mathrm{m}^{3}$ dan telah diusahakan oleh PT. Flora Ria Adi Kencana dan cadangan lain masih dalam tahap penyelidikan.

3. Lempung

Sumberdaya Lempung terdapat dibeberapa wilayah, yaitu

- Wilayah Abe Pantai

Sumberdaya Lempung di wilayah ini dengan jumlah cadangan sebesar 486.802,6 $\mathrm{m}^{3}$ dan Belum ada kegiatan penambangan dan cadangan lain masih dalam tahap penyelidikan.

- Wilayah Tanah Hitam

Sumberdaya Lempung di wilayah ini dengan jumlah cadangan sebesar 98.238,2 $\mathrm{m}^{3}$ dan Belum ada kegiatan penambangan dan cadangan lain masih dalam tahap penyelidikan.

\section{C.2. Produksi}

Berdasarkan data perusahaan yang mengolah tambang mineral batuan yang ada di Kota Jayapura pada tahun 2018, bahwa terjadi peningkatan produksi khusunya endapan batugamping dan batuan beku ultrabasa hal dikarenakan ondisi Kota Jayapura yang terus melakukan perbaikan saran dan prasarana, seperti pelebaran jalan, pengaspalan, pembuatan jembatan serta pembangunan rumah toko (ruko). Salah satu data perusahaan menunjukkan naiknya permintaan akan pemanfataan mineral batuan khususnya batugamping dan batuan beku ultrabasa adalah sebanyak $50 \%$.

\section{C.3. Pemanfaatan Mineral Batuan}

Pada tahun 2018, jumlah pemakaian mineral batuan khusunya batugamping yang tercatat pada bagian pemasaran salah satu perusahaan pengelolah tambang batugamping adalah, secara nominal pemakaian batugamping adalah $43.200 \mathrm{~m}^{3}$ dengan harga jual adalah sebesar Rp.400.000/ret yang dimanfaatkan oleh beberapa kontraktor jalan. Sedangkan untuk konsumsi data mineral batuan yang lain, datanya belum diketahui hal ini dikarenakan kurangnya informasi dari pihak perusahaan sebagai pengelolah tambang tersebut (Tabel 1). 
Tabel 1. Potensi Mineral Batuan di Kota Jayapura

\begin{tabular}{cccccc}
\hline No & Lokasi & Cadangan & Luas Area & Jenis Material & $\begin{array}{c}\text { Pengusaha } \\
\text { Pelaksana }\end{array}$ \\
\hline 1 & $\begin{array}{c}\text { Polimak I, Distrik } \\
\text { Jayapura Selatan } \\
\text { Argapura, Distrik } \\
\text { Jayapura selatan } \\
\text { Koya Koso, Distrik } \\
\text { Abepura }\end{array}$ & $7.575 .403,3 \mathrm{~m}^{3}$ & $8 \mathrm{Ha}$ & Batugamping & CV.Thiak \\
3 & $438.814,5 \mathrm{~m}^{3}$ & $2 \mathrm{Ha}$ & Batugamping & - \\
4 & $\begin{array}{c}\text { Abe Pantai, Distrik } \\
\text { Abepura }\end{array}$ & $4.865 .803,6 \mathrm{~m}^{3}$ & $1,3 \mathrm{Ha}$ & Lempung & - \\
5 & $\begin{array}{c}\text { Yoka Waena, Distrik } \\
\text { Heram }\end{array}$ & $572.408,4 \mathrm{~m}^{3}$ & $5,9 \mathrm{Ha}$ & Beku Ultrabasa & $\begin{array}{c}\text { PT.Jamer } \\
\text { Mandiri }\end{array}$ \\
6 & $\begin{array}{c}\text { Padang Bulan (Ale- } \\
\text { Ale), Distrik Heram }\end{array}$ & $3.270 .567,8 \mathrm{~m}^{3}$ & $1,3 \mathrm{Ha}$ & Beku Ultrabasa & $\begin{array}{c}\text { PT.Floraria } \\
\text { Adi Kencana }\end{array}$ \\
7 & $\begin{array}{c}\text { Perumnas III Waena, } \\
\text { Distrik Heram }\end{array}$ & $2.675 .135,3 \mathrm{~m}^{3}$ & $6,4 \mathrm{Ha}$ & Beku Ultrabasa & - \\
8 & $\begin{array}{c}\text { Tanah Hitam, Distrik } \\
\text { Abepura }\end{array}$ & $98.238,2 \mathrm{~m}^{3}$ & $1 \mathrm{Ha}$ & Lempung & - \\
\hline
\end{tabular}

\section{PEMBAHASAN}

Berdasarkan hasil survey inventarisasi potensi mineral batuan menunjukkan berbagai potensi mineral batuan sebagai mineral unggulan di Kota Jayapura seperti batugamping, batuan beku ultrabasa dan lempung serta beberapa mineral lainnya. Namun kondisi saat ini, potensi mineral batuan yang ada belum dikelolah dengan baik karena belum mendapat perhatian dan penanganan serius baik dari pemerintah terutama lewat dinas terkait maupun investor sektor pertambangan yang ada di Kota Jayapura.

Potensi mineral batuan yang ada di Kota Jayapura apabila ingin dijadikan sebagai mineral unggulan dan dapat memberikan manfaat maka diperlukan beberapa upaya-upaya yang dilakukan, antara lain :

- Perlu dilakukan penelitian yang lebih detail untuk semua sebaran mineral batuan yang ada di Kota Jayapura, sehingga seluruh potensi yang dimiliki dapat dieksploitasi lebih maksimal.

- Perlu dilakukan penelitian dan pengembangan teknologi untuk pemanfaatan kualitas dalam hal ini produk yang dihasilkan dari potensi mineral batuan yang ada.

- Pengembangan wilayah dan perencanaan tata ruang yang diarahlan sesuai konsep pengelolaan sumberdaya mineral yang dapat memberikan manfaat yang besar bagi seluruh aspek kehidupan Kota Jayapura.

- Perlu dilakukan sosialisasi dan bimbingan yang berkesinambungan atau terus menerus dari instansi teknis tentang pengelolaan pertambangan dan lingkungan terhadap pada investor atau pengusaha tambang.

- Program pemberdayaan masyarakat sekitar areal penambangan dengan melihat potensi yang dimiliki sehingga dapat memberikan kesempatan usaha dan kesempatan kerja di sektor pertambangan atau di perusahaan pengelolah kegiatan penambangan tersebut. 


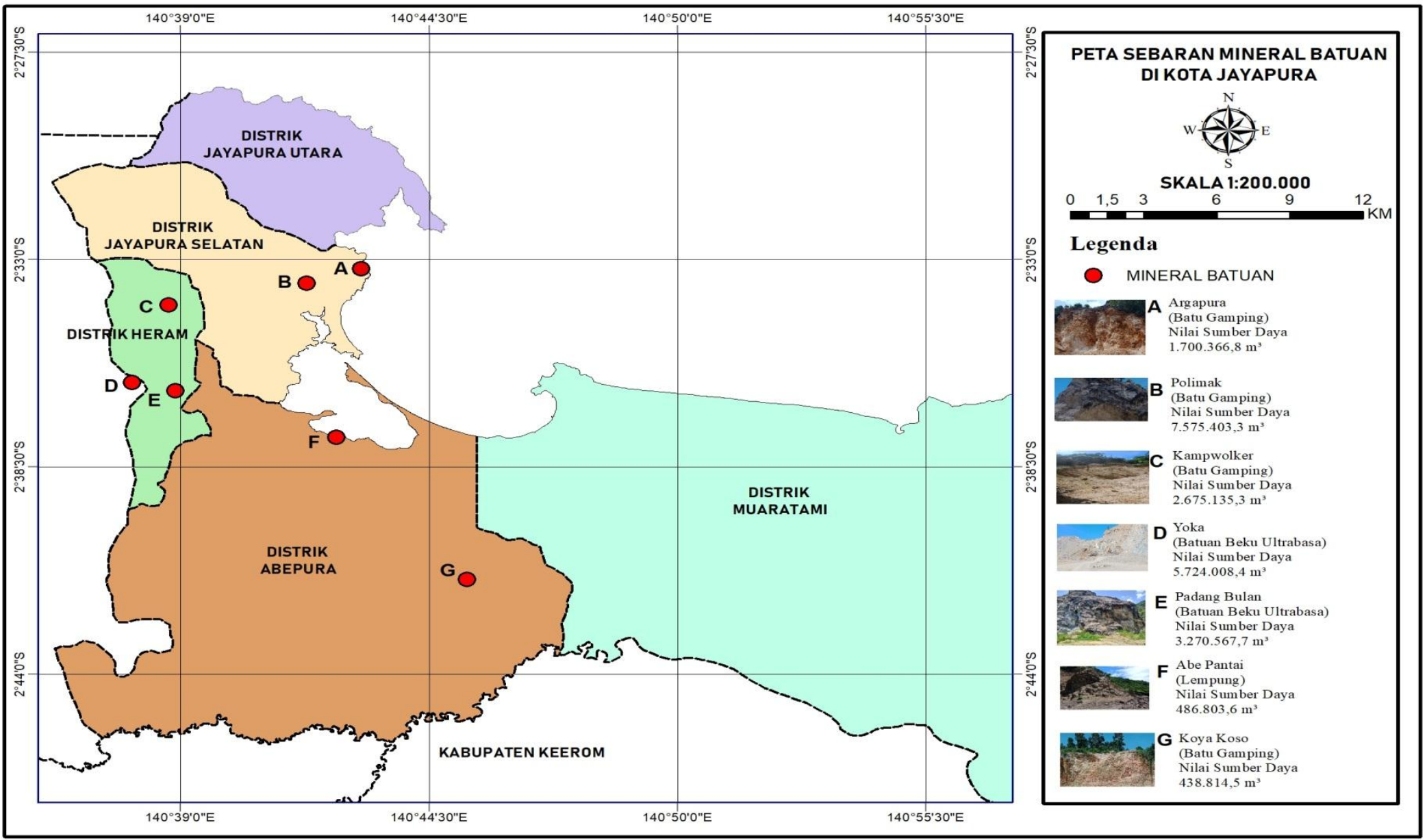

Gambar 2. Peta Sebaran Mineral Batuan 


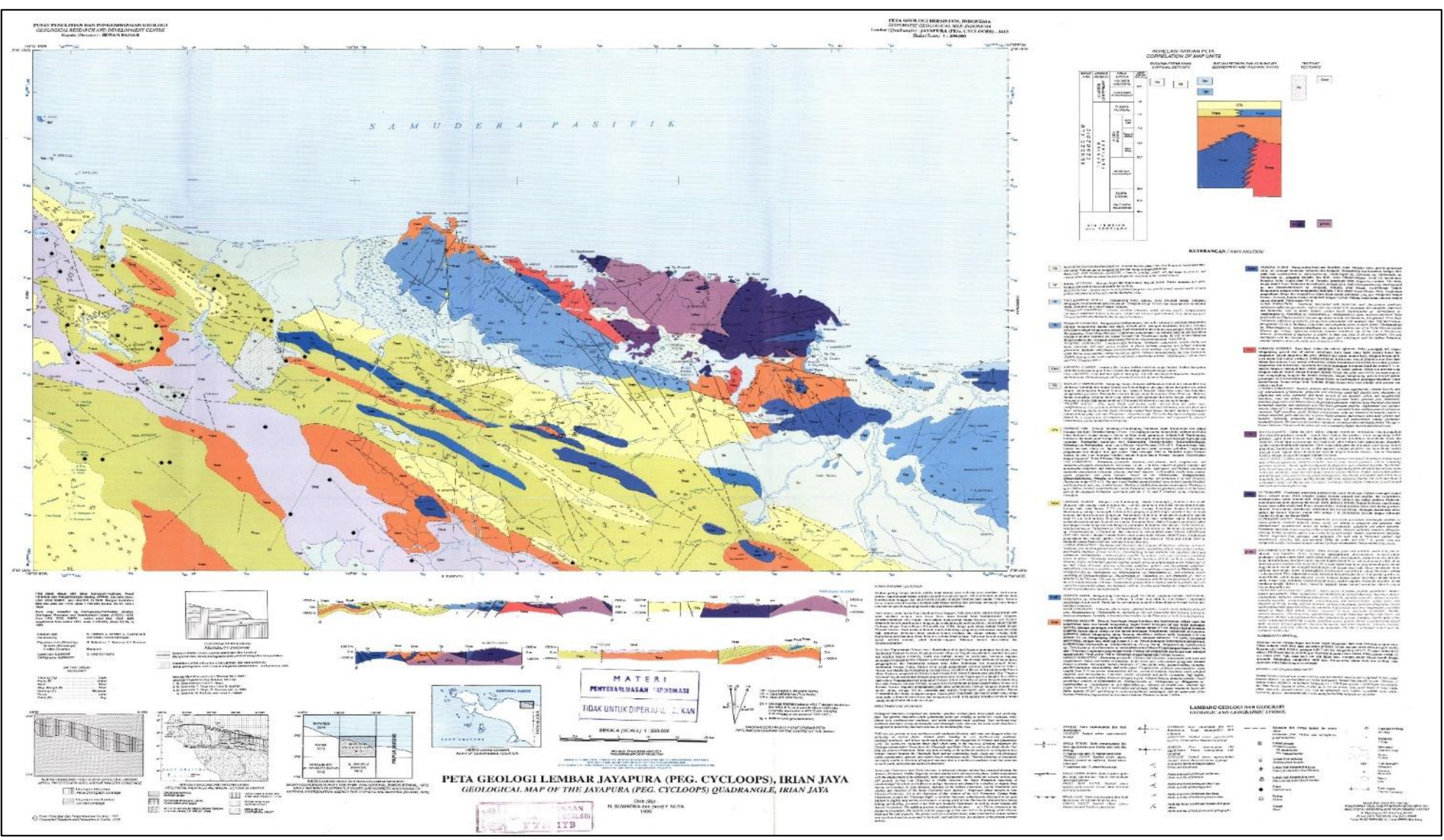

Gambar 3. Lembar Geologi Daerah Jayapura 


\section{KESIMPULAN DAN SARAN}

\section{D.1 Kesimpulan}

Berdasarkan Hasil hasil penelitian yang dilakukan maka dapat disimpulkan bahwa :

1. Potensi mineral batuan yang diusulkan sebagai mineral unggulan Kota Jayapura adalah Batugamping, Batuan Beku Ultrabasa dan Batu Lempung yang penyebarannya paling banyak terdapat di Distrik Heram Kota Jayapura.

2. Peta sebaran mieral batuan yang dibuat dengan menggunakan software ArcGIS10.3. dapat membantu untuk memberikan informasi mengetahui dimana lokasi keterdapatan mineral batuan.

\section{D.2 Saran}

Adapun saran yaitu sebagai berikut :

1. Pada saat kegiatan penambangan nanti, perlu dilakukan kesesuaian antara perencanaan dan aktualisasi dilapangan agar dapat meminimalisir biaya operasional pada saat kegiatan penambangan berlangsung.

2. Perlu dilakukan sosialisasi terhadap kepemilikan lahan atau hak ulayat tentang sebaran batuan beku ultrabasa baik secara teknis dan ekonomis tentang kegiatan penambangan serta dampak yang ditimbulkan.

3. Perlu dilakukan penelitian lanjutan dengan metode perhitungan lainnya agar dapat meningkatkan tingkat keyakinan tentang sebaran mineral batuan.

\section{DAFTAR PUSTAKA}

Abdul Rauf. 1998. Perhitungan Cadangan, Penerbit Yogyakarta

Adjat Sudrajad, 1999. Teknologi dan Manajemen Sumberdaya Mineral, Penerbit ITB Bandung.

Ajun Ferdinandus Leba. 2011. Penaksiran Sumber daya Batubara dengan Metode Cross Section di PT. Stria Mayangkara Sejahtera, Tanjung Telang, Lahat Sumatra Selatan, Universitas Pembangunan Nasional, Veteran Yogyakarta

Doddy Setia Graha, 1987, Batuan dan Mineral,Penerbit Nova Bandung

George J. Young, 1946, Elements of Mining, McGRAW-Hill Book Company, Inc New York and London.

Sutarto , 2008. Endapan Mineral Cadangan Bahan Galian,Teknik Geologi, Universitas Pembangunan Nasional, Veteran : Yogyakarta. 